\title{
Knowledge Management Barriers in Higher Education: Strategic Issues at Private University
}

\author{
Faradillah FARADILLAH $^{1}$, Ermatita ERMATITA ${ }^{2 *}$, and Dian Palupi RINI ${ }^{3}$
}

\author{
${ }^{1}$ Information System, Computer Science Faculty, University of Indo Global Mandiri Palembang Indonesia \\ ${ }^{1}$ Faradillah.hakim@uigm.ac.id, Student of Engineering Doctoral Program Faculty, University of Sriwijaya, Palembang \\ Indonesia \\ ${ }^{2}$ ermatitaz@yahoo.com Information System, Computer Science Faculty, University of Sriwijaya, Palembang Indonesia \\ ${ }^{3}$ dprini@unsri.ac.id, Informatics, Computer Science Faculty, University of Sriwijaya, Palembang Indonesia \\ *Corresponding author: ermatitaz@yahoo.com
}

\begin{abstract}
This study proposes The Knowledge Management Barriers for private universities, data collected in Palembang through an online questionnaire distributed to 131 of ABC University lecturers. The results showed that there were four factors with the same components extracted by Principal Component Analysis (PCA) with each factor consisting of 9, 4, 4 and 5 factors with similar components. These factors are further classified based on similarity of components, namely: Organizational, Technology, Infrastructure, and Environment Barriers. These barrier factors can be used as a reference for private universities in determining $\mathrm{KM}$ strategy to avoid the failure of KM implementation in private universities.
\end{abstract}

Keywords: KM, HEI, barriers

\section{INTRODUCTION}

Data and technology growth are increasing fast, encouraging data processing into useful information, known as Knowledge[1]. The application of Knowledge Management to an organization is something that can provide opportunities for organizational progress, but on the other hand it can also be a challenge for the organization itself[2]. Some of the opportunities and challenges include: the process of creating and maintaining knowledge-excels in terms of relevance, importance, volume, variety, currency, organization, accuracy and security; the process of developing a superior combination of knowledge between humans and machines so as to produce a combination of innovations that have high asset value as knowledge resources; the process of developing a system of documenting experiences as tacit knowledge sourced from experts; the integration of the use of the knowledge base, processors, and processes for superiority as a step in: making sense, predict, evaluate, decision-making [3].

Higher Education Institutions serve as a as reservoir of knowledge and are no longer just providing knowledge to students. These institutions manage, blend, and share knowledge among the faculty staff themselves. Thus, managing knowledge is inevitably challenging and an important concept in higher learning institutions [4]. The main goal of Higher Education Institutions (HEI) are produce and manage knowledge through human activities and technical practices to connect individuals from various levels of administration and sections. Some of the process are to form working groups, built the relationships that produce shares and exchange knowledge they have as the organization culture, support individual and collective learning processes, improving and developing individual and organizational performance. Those processes are called as Knowledge Management (KM)[5].

$\mathrm{KM}$ is defined as a mechanism that includes a systematic process, in which knowledge is created, captured, shared and utilized for the needs of individuals and organizations[1][6][7]. Information practices and learning strategies known as knowledge management are gaining acceptance in the field of education, This is evident by the fact that several higher learning institutions, particularly in the developed world have been receiving grants to implement knowledge management practices[4]. Therefore there is no doubt, $\mathrm{KM}$ is an important activity that must be effectively carried out by organizations worldwide especially for HEI as the Knowledge Creator Places[8]. Given this growing interest, numerous studies have examined issues in the wider context of knowledge management implementation in organizations. However, comprehensive research in the area of knowledge management practice between university faculty staff has been rather limited. Based on previous studies, the authors need to review deep down on strategic issues on $\mathrm{KM}$ implementation at university, especially for private universities in Palembang as an effort to avoid the failure of KM implementation.

\section{KNOWLEDGE MANAGEMENT PROCESSES}

Some previous studies mention $\mathrm{KM}$ processes as: Creation/acquisition, modification, use, archiving, transfer, translation, access, and disposal, transmission, utilisation, packaging and assembly, application, reuse, and revalidation of knowledge [9][10][11][12][13]. Nonaka, Toyama and Konno introduced the four KM processes as Socialization, Externalization, Internalization. And Combination[14]. Becerra and Fernandez define that knowledge management processes as Knowledge Capture, Sharing, Application, and Discovery [15].

Knowledge Management in Higher Education Institution (HEI)

Higher Education Institutions (HEIs) are places to create and disseminate knowledge through research, publications and by supporting learning and innovation[16]. The 
existence of knowledge management practices in educational institutions is believed to help build the future of a dynamic academic environment, the development and improvement of the efficiency of sharing, transfer, acquisition, creation and reuse of knowledge that will improve overall organizational performance in the end [17][18][19][20].
Knowledge Management Barriers in Private University KM Barriers, are factors that have a negative effect and the probability of its being beneficial on $\mathrm{KM}$ implementing [21][22]. KM Barriers that was found in the previous research summarized on Table 1 [21][22][23][24][25]. Next those barrier factors are named as X1 into X22 when the PCA running on SPSS such Table 1 presented.

Table 1 Barrier Factors found on Previous Study

\begin{tabular}{|c|c|}
\hline CODE & BARRIER FACTORS \\
\hline $\mathrm{X} 1$ & $\begin{array}{l}\text { Lack of policies and rewarding mechanisms to encourage and promote } \\
\text { research }\end{array}$ \\
\hline $\mathrm{X} 2$ & Lack of vision lack of resources and funding for research \\
\hline $\mathbf{X 3}$ & Limited access to data and databases \\
\hline $\mathrm{X4}$ & Heavy workload due to teaching and administrative duties \\
\hline $\mathrm{X5}$ & Fewer multi-disciplinary and inter-institutional research projects \\
\hline X6 & Difficulty in obtaining research grants \\
\hline $\mathbf{X} 7$ & Lack of a knowledge sharing culture \\
\hline X8 & $\begin{array}{l}\text { Promotion policy leading to individualistic and competitive behaviour, } \\
\text { mistrust, fear, crab mentality }\end{array}$ \\
\hline X9 & Lack of incentives to encourage knowledge sharing \\
\hline X10 & Frequent leadership changes \\
\hline X11 & $\begin{array}{l}\text { Weak industry-academia linkage lack of interactive web portal/research } \\
\text { repository }\end{array}$ \\
\hline $\mathrm{X12}$ & Possibility of the loss of documents \\
\hline X13 & $\begin{array}{l}\text { Low compatibility of document management systems used by different } \\
\text { subdivisions }\end{array}$ \\
\hline $\mathrm{X14}$ & Absence of possibility of simultaneous document editing by different users \\
\hline $\mathrm{X15}$ & Ambiguous subordination structure \\
\hline $\mathrm{X} 16$ & Ambiguous job instructions \\
\hline $\mathbf{X 1 7}$ & Lack of understanding of what employee has what knowledge \\
\hline $\mathrm{X18}$ & $\begin{array}{l}\text { Lack of motivation to share knowledge as activities not included into the } \\
\text { regular job duties }\end{array}$ \\
\hline $\mathbf{X 1 9}$ & Excessive communication processes centralization \\
\hline $\mathbf{X 2 0}$ & $\begin{array}{l}\text { Low compatibility of document management systems used by different } \\
\text { subdivisions }\end{array}$ \\
\hline $\mathrm{X} 21$ & $\begin{array}{l}\text { Possibility of loss of documents in the all- university obligatory document } \\
\text { management system }\end{array}$ \\
\hline $\mathbf{X 2 2}$ & Lack of having good infrastructure \\
\hline
\end{tabular}


Table 1 shows that there are 22 factors found from previous studies that will be analyzed and extracted based on their principal components.

\section{Principal Component Analysist (PCA)}

Principal component analysis (PCA) is a multivariate analysis technique which aims to explain the relationship between some variables are difficult to interpret, correlated in terms of from some conceptually meaningful components that are do not correlate with each other through linear transformations of the original variable become a set of new variables which are referred to as principal components that are not correlated with each other. PCA uses an approach interpretation of the main components is acceptable if the main component is extracted using the $\mathrm{R}$. variance-covariance matrix as well used to obtain the main components, since the principal component engineering depends on scale, in principle loading components with this approach is therefore much influenced by the unit of measurement the variables considered. Therefore, are interpretations the main components are only based on their magnitude loading [26][27][28].

\section{RESULTS AND DISCUSSION}

This research was conducted at $\mathrm{ABC}$ university in Palembang, with a total of 131 lecturers as respondents by random sampling technique. Data collection was done by distributing manual and online questionnaires and collected 100 items data set. The results of data processing using SPSS 22 Version shows that the value of Kaiser Meyer Olkin Measure of Sampling score 0.831 which more than 0.5 so that the proposed barrier factors are valid [29]. The detail score of Kaiser Meyer Olkin Measure of shows on Figure 1.

KMO and Bartlett's Test

\begin{tabular}{|ll|r|}
\hline Kaiser-Meyer-Olkin Measure of Sampling Adequacy & 0.831 \\
Bartlett's Test of Sphericity & Approx. Chi-Square & 1445.952 \\
& df & 453 \\
& Sig. & 0 \\
\hline
\end{tabular}

Figure 1 The Result of KMO and Bartlett's Test

The score for Communalities of all factors are also show more than 0.5 which means the factors proposed describe the barriers on KM implementation properly[26]. The result of final matrix rotation shows that the factors divide into 4 factors classification that have similarity principal components as Figure 2 showed.

\begin{tabular}{|c|c|c|c|c|}
\hline & \multicolumn{4}{|c|}{ Rotated Component Matrix } \\
\hline & & & & \\
\hline & 1 & 2 & 3 & 4 \\
\hline$\times 1$ & .863 & .091 & .073 & .087 \\
\hline$\times 2$ & .851 & 142 & .327 & -009 \\
\hline$\times 4$ & .833 & .106 & 201 & 019 \\
\hline$\times 9$ & 811 & .287 & 172 & -.190 \\
\hline$\times 10$ & .807 & -.051 & .079 & .033 \\
\hline$\times 15$ & .789 & .165 & -0.44 & -0.01 \\
\hline$\times 16$ & .775 & .253 & -.147 & 277 \\
\hline$\times 19$ & .743 & .231 & .099 & -.031 \\
\hline$\times 8$ & .741 & -.243 & 129 & .053 \\
\hline$\times 13$ & 206 & .729 & 187 & 131 \\
\hline$\times 20$ & .010 & .722 & .206 & .233 \\
\hline$\times 3$ & .187 & .718 & .010 & .031 \\
\hline$\times 11$ & .080 & .710 & .090 & -.289 \\
\hline$\times 12$ & 171 & -.168 & .709 & -218 \\
\hline$\times 14$ & .059 & -.43 & .704 & -.244 \\
\hline$\times 22$ & .169 & -.218 & .730 & .344 \\
\hline$\times 21$ & .321 & .006 & 698 & .150 \\
\hline$\times 5$ & .117 & -.017 & 112 & .694 \\
\hline$\times 6$ & .113 & .222 & .083 & .687 \\
\hline$\times 7$ & .010 & .215 & 152 & 658 \\
\hline$\times 18$ & .204 & .033 & -199 & 655 \\
\hline$\times 17$ & -.057 & .013 & .044 & .631 \\
\hline
\end{tabular}

Figure 2 The Result of Final Rotation Matrix

The result of Kaiser Meyer Olkin Measure shows four (4) component classification consisting each barrier factors on KM implementation:

- Factors 1(one) including X1, X2, X4, X9, X10, $\mathrm{X} 15, \mathrm{X} 16, \mathrm{X} 19$, and $\mathrm{X} 8$ are named as Organizational Barriers

- Factors 2 (Two) including: X13, X20, X3 and $\mathrm{X} 11$ are named as Technology Barriers

- Factors 3 (Three) including X12, X14, X22 and $\mathrm{X} 21$ are named as Infrastructure Barriers

- $\quad$ Factors 4 (Four) including X5, X6, X7, X18 and $\mathrm{X} 17$ as named as Environment Barriers

The factors are classified by the similarity principle of components, named according to the characteristics of the factors based on KM enablers which have also been widely studied before[30], [31][32][33]. In this study, the results show the quite same of previous studies are in other countries, but the factor of education providers whose formed as foundations with centralized and traditional governance is also crucial issue that needs to be considered in depth for the successful implementation of KM.

\section{CONCLUSION}

The results of this study are the classification of barrier factors on $\mathrm{KM}$ implementation in private universities in Palembang, among others Organizational include: lack of policies and rewarding mechanisms to encourage and promote research; lack of vision lack of resources and funding for research; heavy workload due to teaching and administrative duties; promotion policy leading to individualistic and competitive behavior, mistrust, fear, crab mentality; lack of incentives to encourage knowledge sharing; frequent leadership changes; ambiguous subordination structure; ambiguous job instructions; low compatibility of document management systems used by different subdivisions; Technology include: weak industry academia linkage lack of interactive web portal/research repository; limited access to data and databases; low compatibility of document management systems used by different subdivisions; excessive communication processes centralization; Infrastructure include: possibility of the loss of documents; absence of possibility of simultaneous document editing by different users; possibility of loss of 
Advantage in Local Authorities using Knowledge Management Assessment Instrument ( KMAI )," IGI Global Disseminator of Knowledge, pp. 294-314, 2014.

[11] J. Makani, "Knowledge management, research data management, and university scholarship: Towards an integrated institutional research data management support-system framework," Vine, vol. 45, no. 3, pp. 344-359, 2015.

[12] P. Akhavan, R. Hosnavi, and M. E. Sanjaghi, "Identification of knowledge management critical success factors in Iranian academic research centers," 2009.

[13] H. H. Mohammad, F. H. Mohammad, S. Ali, and N. B. Ali, "The Influence of Knowledge Management Capabilities on Organizational Performance: A Study of Private University in Malaysia," International Journal of Science and Research, vol. 3, no. 10, 2014.

[14] I. Nonaka, R. Toyama, and N. Konno, "SECI, Ba and Leadership: A Unified Model of Dynamic Knowledge Creation," Long Range Planning, 2000.

[15] I. Becerra-Fernandez and Rajiv Sabherwal, Knowledge Manamgement Systems and Processes. 2010.

[16] R. F. Santos, P. S. De Garcia, and M. Oliveira, "What influences knowledge hoarding in postgraduate students? An empirical research in universities,"

Proceedings of the European Conference on

Knowledge Management, ECKM, vol. 1, pp. 278-285, 2018.

[17] O. F. Al Kurdi, "Knowledge-Sharing Management in the Context of Higher Education Institutions," 2017.

[18] T. Kaya and B. Erkut, "Tacit Knowledge Capacity: A Comparison of University Lecturers in Germany and North Cyprus," The Electronic Journal of Knowledge Management, vol. 16, no. 2, pp. 131142,2018

[19] P. Songsangyos, "The Knowledge Management in Higher Education in Chiang Mai: A Comparative Review," Procedia - Social and Behavioral Sciences, vol. 69, no. Iceepsy, pp. 399-403, 2012.

[20] A. Alshahrani, "Critical Success Factors of Knowledge Management in Higher Education Institutions : A Comparative Study between Western Sydney University in Australia and King Fahd Security College in Saudi Arabia,” pp. 1-342, 2018.

[21] P. Veer Ramjeawon and J. Rowley, "Knowledge management in higher education
[10] A. Hassan and A. Bakar, "Assessing Knowledge Management Processes and Competitive 
strategy," Journal of Knowledge Management, vol. 21, no. 2, pp. 308-329, 2017. institutions: enablers and barriers in Mauritius," Learning Organization, vol. 24, no. 5, pp. 366-377, 2017.

[22] E. Blagov, A. Pleshkova, E. Soldatkin, and N. Koritckiy, "Knowledge Sharing Barriers in the Educational Program Management Administrative Processes: A Case of a Bachelor Program in a Russian University.," Electronic Journal of Knowledge Management, vol. 15, no. 2, pp. 113-125, 2017.

[23] J. Ghafourian, "An exploration study to detect important barriers for knowledge management," Management Science Letters, vol. 4, pp. 25-30, 2014.

[24] S. I. Ceptureanu, E. G. Ceptureanu, M. Olaru, and D. I. Popescu, "An exploratory study on knowledge management process barriers in the oil industry," Energies, vol. 11, no. 8, pp. 1-16, 2018.

[25] G. O. Okere, "Barriers and enablers of effective knowledge management: A case in the construction sector," The Electronic Journal of Knowledge Management, vol. 15, no. 2, pp. 85-97, 2017.

[26] Novinka, Mathematics Research Developments, Principal Component Analysis (Methods, Applications and Technology). New York: Nova Science Publisher, Inc, 2017.

P. Sanguansat, Principal Component Analysis. 2012.

[28] H. B. Umar, "Principle Component Analysis (PCA) dengan Aplikasi SPSS," Jurnal Kesehatan Masyarakat, vol. 03, 2009.

[29] "Principal Components and Exploratory Factor Analysis Today' s Lecture s x What it is How it works How to do such an analysis Comparisons to PCA," 2011.

[30] A. Anand, A. Csepregi, and E. Bogdány, "Barriers to knowledge creation in SMEs: Preliminary study results from India," Proceedings of the European Conference on Knowledge Management, ECKM, vol. 1, pp. 67-73, 2018.

[31] M. Zikmund, "Review of supply chain knowledge management literature add-on: Closing the gaps," Proceedings of the European Conference on Knowledge Management, ECKM, vol. 2, no. 2012, pp. 1124-1130, 2018.

[32] W. Wu, "Segmenting critical factors for successful knowledge management implementation using the fuzzy DEMATEL method," Applied Soft Computing Journal, vol. 12, no. 1, pp. 527-535, 2012.

[33] R. Dayan, P. Heisig, and F. Matos, "Knowledge management as a factor for the formulation and implementation of organization 